\title{
Clinical and dosimetric consequences of imperfect applicator insertion in cervical cancer brachytherapy
}

\author{
Bikramjit Chakrabarti, MD, DNB, Suparna Kanti Pal, MD, Harris Mahammad Sepai, MD, Somapriya Basu Roy, MSc, PhD, \\ Sanjay Kr. Kar, MSc, Annesha Lahiri, MBBS, Sounik Das, MBBS, Amit Bala, MBBS \\ Department of Radiotherapy, Institute of Post-Graduate Medical Education and Research and Seth Sukhlal Kernani Memorial Hospital, \\ Kolkata, India
}

\begin{abstract}
Purpose: This study analyzes clinical consequences and dosimetric variations after imperfect brachytherapy insertions. It examines treatment decisions after such insertions in patients having difficult anatomy, which leads to good subsequent insertions with acceptable dose volume parameters.

Material and methods: We reviewed images of all insertions performed during last one year and sorted faulty ones out. Clinical outcome was assessed, analyzing original treatment records. Repeat three-dimensional planning using identical dose-optimization-technique compared their dosimetry. Statistical analysis using SPSS ${ }^{\circledR}$-Statistics-software included Fisher's-exact-test to analyze predisposing factors for faulty insertions and predictive factors for subsequent satisfactory insertion. Friedman test was used to compare dose-volume-effects of normalization.

Results: Eighteen of 292 brachytherapy plans revealed imperfect insertions, including thirteen perforations (4.5\%). Lack of pre-planning, obstructing mass, narrow vagina, acute anteversion of uterus, and multi-parity were significant $(p \leq 0.05)$ predisposing factors for atypical insertions. Satisfactory optimization was possible after correcting acute anteflexion or positioning tandem in retroverted direction in uncorrectable retroverted uterus. Dose normalization at point A shifted optimized dose from contoured volume to point of normalization, often undesirably. This difference, however, was statistically not significant $(p=0.121)$. In patients having obstructing mass, subsequent insertions were perfect, and dose volume parameters were acceptable only when full prescribed dose was delivered to at least $60 \%$ volume of the mass after a faulty insertion $(p<0.001)$.

Conclusions: Pre-planning by imaging is suggested in all cases of brachytherapy. Insertion of adequate length of tandem aligned to uterine axis is warranted for adequate tumor coverage. Whenever detected, acute anteflexion and mobile retroversion should be corrected. Tandem inserted in retroverted direction in uncorrectable retroverted uterus generates acceptable dose volume parameters. In cases with obstructive cervical mass, good subsequent insertion is possible with acceptable dose volume parameters, if planned dose can be delivered to its $60 \%$ volume.
\end{abstract}

J Contemp Brachytherapy 2018; 10, 4: 321-336 DOI: https://doi.org/10.5114/jcb.2018.77954

Key words: applicator, brachytherapy, cervical cancer, difficult, dose-volume, guidelines, problem, insertion.

\section{Purpose}

Cervical cancer is the third most common cancer worldwide and has an annual mortality rate of 270,000 worldwide [1]. Brachytherapy plays an anchor role in management of locally advanced disease. In recent years, imaging has been incorporated into brachytherapy treatments [2]. The dose to the target and organs at risk (OAR) can be optimized based on the anatomical situation at the time of brachytherapy [3]. A choice of brachytherapy applicator is rather arbitrary [4]. Ring applicators, after graphical optimization alone, generates desired dose vol- ume parameter in all high-dose-rate fractionation schedules. Fletcher applicator may require additional judicious activation of dwell positions to generate desired dose volume parameters in some dose fractionation schedules [5]. However, it is difficult for optimization alone to cover a large or an asymmetrical tumor without significantly increasing the dose to OAR [6]. Tumors with significant residual disease or unfavorable topography after external beam radiotherapy (EBRT) may still represent a therapeutic challenge for conventional brachytherapy [6].

Optimal placement of the tandem and ovoids is always essential for an acceptable brachytherapy plan [7]. 
Since the dose distribution in brachytherapy follows inverse square law, a little change in position of tandem creates pronounced dosimetric deviations. Technical adequacy of brachytherapy application is the most important prognostic discriminant factor of local control. A strong trend towards improved 5-year survival is also noted if intracavitary insertion is ideal ( $60 \%$ vs. $40 \%)$ in patients with locally advanced cervical cancer [8].

A

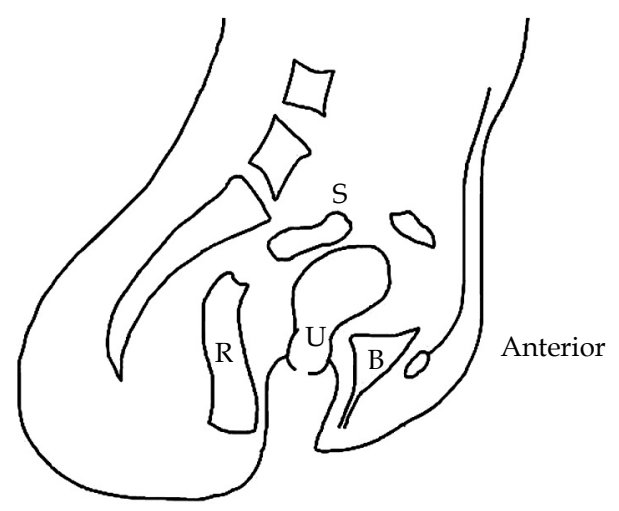

C

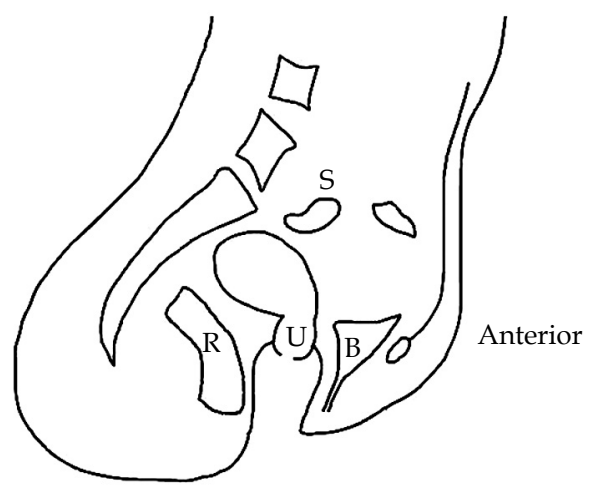

E

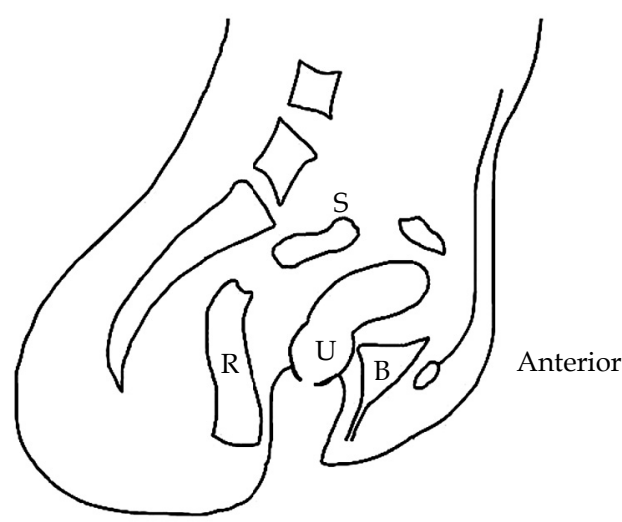

Perfect positioning of uterine tandem is difficult at times if there is altered utero-vaginal anatomy (Figure 1), obstruction by tumor mass, stenosis of cervical canal, or extremely narrow vagina. In an experienced hand, such improper placing of tandem or uterine perforations may occur even after pre-insertion imaging. Treatment outcome worsens further, if successful repeat insertion is not possible.
B

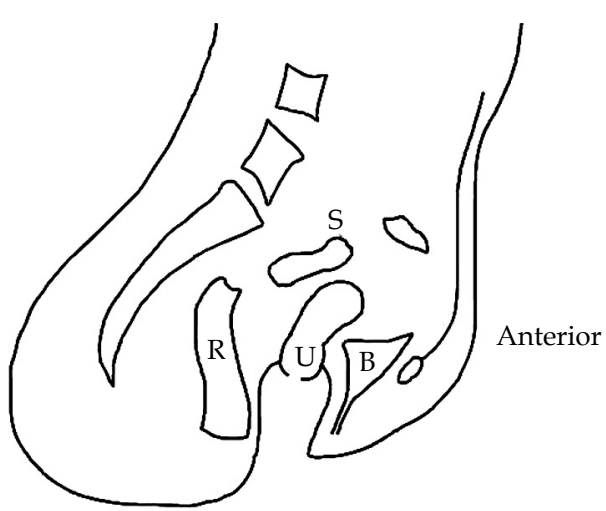

D

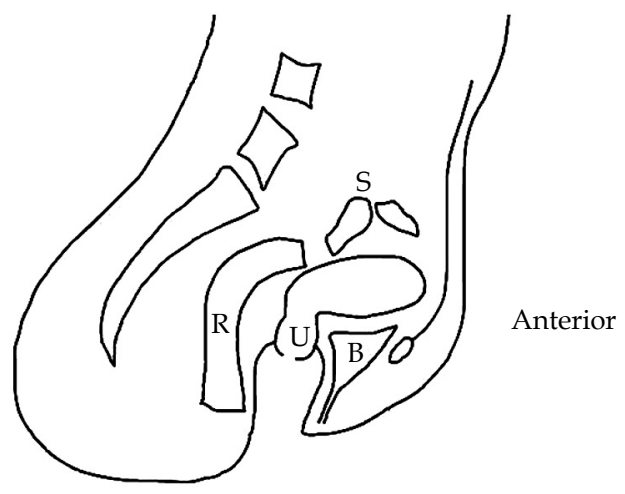

$\mathbf{F}$

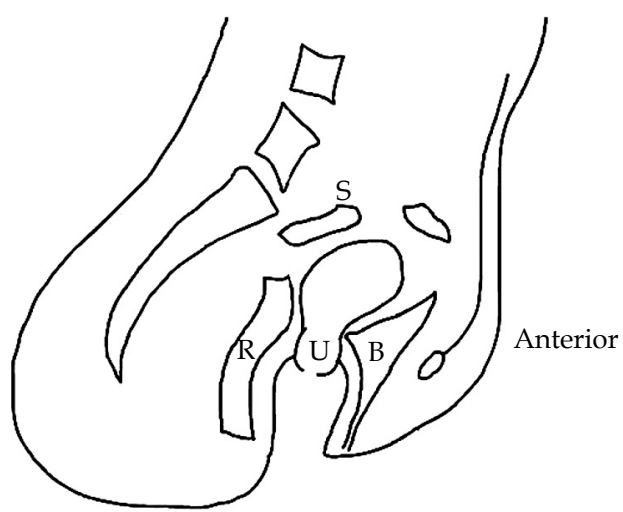

Fig. 1. Diverse anatomical situations during brachytherapy of cervix (sagittal view) ( $\mathrm{R}$ - rectum, $\mathrm{U}$ - uterine cervix, B - urinary bladder, S - sigmoid colon). Pre-planning by computed tomography (CT) scan before applicator insertion helps to detect these situations and reduces chances of imperfect insertions. A) Normal sized and anteverted uterus, B) short uterus: there is a risk of fundal perforation. Sigmoid colon lies close to uterine fundus; C) retroverted uterus: there is risk of anterior uterine perforation. Retroversion is uncorrectable at times, due to attendant pelvic disease; D) acutely anteflexed uterus: there is chance of posterior perforation. Rectum leans on the uterine body, which, on the other hand, pushes down urinary bladder; E) presence of obstructing cervical mass: satisfactory insertion is often difficult. Perforation through mass may occur; F) urinary bladder or rectum is close to uterine body: there is chance of high-dose to these organs, since vaginal packing does not distance them from uterus. Apart from these situations, stenosis of cervical os and extremely narrow vagina cause difficulty in brachytherapy insertion 
Till date, very few publications studied faulty insertions. Although, there are some studies evaluating incidence of perforation after brachytherapy, no publication has analyzed systemically both dosimetric and clinical consequences of unsatisfactory insertions. Our study analyzes incidence, causes, clinical consequences, and dosimetric alterations after different imperfect insertions, in addition to perforation. It aims at finding out suitable treatment decisions after faulty insertions in patients having difficult anatomy (like residual obstructing cervical mass, acute anteflexion, fixed retroversion, narrow vagina etc.), which will guide to a good subsequent insertion with acceptable dose volume parameters.

\section{Material and methods}

At Institute of Post-graduate Medical Education and Research, nearly three hundred newly-diagnosed cases of cervical cancer are treated every year. Patients treated with curative intent receive a dose of 50 Gy EBRT in conventional fractionation using four-field box technique. Computerized tomographic (CT) image-based three-dimensional (3D) volume delineation is done for EBRT planning. Concomitant chemotherapy with cisplatin $100 \mathrm{mg} / \mathrm{m}^{2}$ three times weekly is done during EBRT. In patients with extensive parametrial disease, a further 10 Gy parametrial boost in conventional fractionation is delivered by parallel opposed antero-posterior beams.

Brachytherapy is usually done after completion of EBRT. However, in patients receiving parametrial boost, brachytherapy insertions are intertwined between the parametrial boost fractions to keep the total duration of treatment within eight weeks. When interdigitating brachytherapy, caution is taken not to administer weekly chemotherapy on a brachytherapy day but to deliver rather on an EBRT day to avoid the possibility of increased adverse effects due to normal-tissue sensitization.

Clinical assessment including per-speculum and per-vaginal examination is completed before brachytherapy. Pelvic ultrasonography or CT scan is done before applicator insertion in select cases to assess response or to exclude co-morbidities. Oral anxiolytic and stool softener are given to patients the night before brachytherapy procedure. CT compatible applicators (generally tandem-ring or Fletcher-Suit style tandem-ovoid intracavitary applicators) are inserted under intravenous sedation. All patients undergo a CT scan (3 mm slice) using Philips Brilliance CT simulator (Philips Healthcare, Inc., Andover, MA) with applicators in position. Oncentra ${ }^{\circledR}$ Brachy version 4.5.2 treatment planning system (Nucletron, an Elekta company, Stockholm, Sweden) is used for three-dimensional (3D) treatment planning. Whole of the cervix with any parametrial extension is contoured following the guideline by American Brachytherapy Society (ABS) cervical cancer brachytherapy task group [9], extending superiorly up to the location where the uterus began to enlarge. If this cannot be identified, a height of $3 \mathrm{~cm}$ is contoured for the cervix. A portion of tandem inside the cervix is included in the contoured clinical target volume (CTV). The whole of urinary bladder inclusive of the Foley's catheter bulb, whole of rectum and sigmoid colon are contoured as organs at risk. The usual practice at our department is prescription of 7-8 Gy for three fractions, normalized at point A. A dose of 79.8-86 Gy, two gray equivalent dose $\left(\mathrm{EQD}_{2}\right)(\alpha / \beta=10)$ is thus delivered to the $100 \%$ isodose curve passing through this point. Optimization is done to ensure CTV coverage and to reduce dose to organs at risk as necessary. Prescription is reviewed by treating oncologist, and radiation safety is checked by the radiation safety officer. Procedure of brachytherapy insertion including use of intravenous sedation, CT imaging, and prescription of dose to point $\mathrm{A}$ are all in accordance with 'modifications from American Brachytherapy Society (ABS) 2012 consensus guidelines for practice in resource-limited settings (RLSs)' [10]. Treatment is affected using ${ }^{192}$ Ir source in HDR-microselectron brachytherapy set-up (Nucletron, an Elekta company, Stockholm, Sweden). Clinical records are maintained for each patient.

For our study, we reviewed all saved image sets and 3D plans of brachytherapy insertions performed during last one year. We sorted out cases of improper positioning of intracavitary applicators including uterine perforation. Perforation was defined as visibility of applicator tip beyond uterine or vaginal musculature in CT scan. Types and causes of imperfect insertions were analyzed. Clinical records of patients were reviewed.

3D plans made for treatment after such imperfect brachytherapy application had originally used different dose optimization techniques. Hence, to compare dose volume effects between different unsatisfactory insertions, we performed repeat 3D planning and optimization with uniform dose optimization technique. The intent was to deliver a minimum of $100 \%$ of prescribed dose to $90 \%$ volume $\left(\mathrm{D}_{90}\right)$ of $\mathrm{CTV}$, less than $75 \mathrm{~Gy}$, two gray equivalent dose $\left(E Q D_{2}\right)$ to $2 \mathrm{cc}\left(\mathrm{D}_{2 \mathrm{cc}}\right)$ volume of rectum and sigmoid colon, and less than $90 \mathrm{~Gy} \mathrm{EQD}_{2}$ to $2 \mathrm{cc}$ volume of urinary bladder, as recommended currently $[9,11,12]$. However, if this was not possible, priority was given to constrain dose to organs at risk. Plan that delivered the best optimized dose to CTV was chosen. Prescription of 7 Gy was done in all cases during repeat dosimetry to ensure comparability. Initially, we planned to compare plans after normalization at point A. However, unnormalized plans with prescription of treatment dose to $100 \%$ isodose line generated by graphical optimization were actually compared, since normalized plans often produced gross dose volume variations.

For assessment of complications and clinical outcome in terms of successful subsequent insertion with acceptable dose volume parameters, we reviewed clinical records of patients and original brachytherapy treatment plans. We analyzed actual delivered dose to different contoured volumes of interest in the initial plans. Longterm effects were not analyzed.

\section{Statistical analysis}

IBM $^{\circledR}$ SPSS ${ }^{\circledR}$ Statistics software version 20 was used for data analysis. Fisher's exact test was used to analyze predisposing factors for faulty insertions and predictive factors for subsequent satisfactory insertion. Non-parametric Friedman test was used to compare dose-volume param- 
eters generated with or without normalization for anterior or posterior deviation of tandem. $P$ value $\leq 0.05$ was considered significant. $\mathrm{EQD}_{2}$ calculations had been done using linear quadratic (LQ) spreadsheet available at American Brachytherapy Society's http://www.americanbrachytherapy.org/guidelines/LQ_spreadsheet.xls website.

\section{Results}

Our study found eighteen plans (Table 1) showing imperfect insertions out of total two hundred and ninety-two planning done (incidence equals to $6.2 \%$ ) during last one year. Out of these, thirteen had perforation (incidence equals to $4.5 \%$ ), and five other plans showed inadequate applicator insertion (Table 2). One had short introduction of tandem due to uncorrected acute anteflexion of uterus, and one had improper selection of tandem

Table 1. Patient characteristics according to stage of disease out of eighteen brachytherapy plans showing imperfect insertions

\begin{tabular}{lcc} 
Stage of the disease & Number of plans & Percentage \\
\hline IIA & 2 & 11.1 \\
\hline IIB & 5 & 27.8 \\
\hline IIIB & 11 & 61.1
\end{tabular}

angulation. Another patient had extremely narrow vagina, in whom insertion was attempted by three different techniques in three insertions. These were tandem alone insertion, tandem with single ovoid insertion, and intracavitary tandem with implant of four interstitial needles through vaginal fornices.

Out of thirteen plans showing uterine perforation, nine had associated residual cervical mass (incidence $69.2 \%$ ). Perforation through uterine musculature was more common (twelve instances) than through friable cervical mass, which was seen in only one patient. Fixed retroverted uterus was the most common (four out of five cases) cause of anterior perforation. Four patients had posterior perforation. Two of them had acute anteflexion of uterus and other two had cervical os hidden behind anterior lip of anteverted uterus. Central fundal perforation was seen in four cases. All of them had a small uterus. Both tandem-ring and Fletcher type tandem-ovoid applicators were associated with uterine perforation. Only one patient had uterine perforation after insertion of ring applicator, as it was less practiced in difficult cases due to its fixed applicator geometry.

\section{Clinical consequences of perforation}

Most of the documented cases of perforation were manageable after close observation for two to three hours with sedation, coagulants, and vaginal packing when re-

Table 2. Types of improper insertions and associated anatomical risk factors

\begin{tabular}{|c|c|c|c|c|c|}
\hline Type of improper insertion & $\begin{array}{l}\text { Number of } \\
\text { plans }\end{array}$ & $\begin{array}{c}\text { Residual tumor } \\
\text { present }\end{array}$ & $\begin{array}{c}\text { Retroverted } \\
\text { uterus }\end{array}$ & $\begin{array}{c}\text { Acute anteverted } \\
\text { uterus }\end{array}$ & Small uterus \\
\hline Anterior perforation & 5 & 2 & 4 & - & 1 \\
\hline Central perforation & 4 & 3 & - & - & 4 \\
\hline Posterior perforation & 4 & 4 & - & 2 & - \\
\hline Short insertion & 1 & - & - & 1 & - \\
\hline Improper angulation of tandem & 1 & - & - & 1 & - \\
\hline Narrow vagina, alternative application & 3 & 3 & - & - & - \\
\hline Total & 18 & 12 & 4 & 4 & 5 \\
\hline
\end{tabular}

Table 3. Clinical consequences of imperfect insertions

\begin{tabular}{llccc} 
Type of improper insertion & $\begin{array}{c}\text { Number } \\
\text { of instances }\end{array}$ & $\begin{array}{c}\text { Requirement for } \\
\text { in-patient care }\end{array}$ & $\begin{array}{c}\text { Units of concentrated } \\
\text { red blood cell needed } \\
\text { for persistent vaginal } \\
\text { bleeding }\end{array}$ & $\begin{array}{c}\text { Damage to bowel } \\
\text { or bladder/death }\end{array}$ \\
\hline Anterior perforation & 5 & 1 & 2 & 0 \\
\hline Central perforation & 4 & 0 & 4 & 0 \\
\hline Posterior perforation & 4 & 1 & 0 & 0 \\
\hline Short insertion & 1 & 0 & 0 & 0 \\
\hline Improper angulation of tandem & 1 & 0 & 2 & 0 \\
\hline Narrow vagina, alternative application & 3 & 1 & 8 & 0
\end{tabular}


quired (Table 3). However, persistent oozing of blood from friable cervical mass or associated vaginal lacerations needed in-patient care usually for next 24 hours. Concentrated red blood cell (CRBC) transfusion was required in three patients of perforation. All had obstructing residual cervical mass. Two of them were managed with two units of CRBC, whereas patient having posterior perforation through cervical mass required four units. The patient with narrow vagina also required two units of concentrated red blood cell transfusion after needle implant. Injury of bladder or bowel was not seen after perforation in any patient.

Brachytherapy dose delivery was abandoned by treating oncologist in one case of fundal perforation after detection. Repeat insertion was done carefully and was successful. Another patient rapidly developed lung and liver metastasis after posterior perforation through friable cervical mass. Further insertions were abandoned, and she was put on palliative chemotherapy. Brachytherapy dose was delivered in all other cases of improper insertion after proper optimization with a hope for successful subsequent insertion.

\section{Analysis of risk factors}

Lack of pre-planning by imaging (to determine uterine size, position, and to exclude obstructing cervical mass) $(p=0.005)$, extremely narrow vagina $(p<0.001)$, and obstructing cervical mass $(p<0.001)$ itself were significant predisposing factors for atypical insertions. Acute anteflexion of uterus $(p=0.022)$ and multi-parity (three or more) $(p=0.045)$ were other significant factors.
Older age, retroverted uterus, stenotic os etc. were not significant risk factors $(p>0.05)$ (Table 4$)$.

\section{Effects of normalization}

During repeat dosimetry, any attempt to normalize dose at point A shifted graphically-optimized dose from the contoured target volume to the point of normalization. This, in cases of anterior or posterior perforation, resulted in lowering of dose to target volume and increase of dose to organs at risk (Figure 2). In central perforation, if tandem is activated to a longer length, normalization created greater volume of $100 \%$ dose and high-dose to volumes of interest (VOI). Statistical analysis by Friedman test, however, indicated the difference between dose-volume parameters generated with or without normalization as non-significant $(p=0.05)$ (Table 5).

\section{Dose to clinical target volume}

Even after best attempts for optimization during repeat dosimetry, anterior or posterior deviation of tandem (Tables 6A-B; Figures 3-5) and short tandem insertions (Table 6C, Figure 6) resulted in lower dose to CTV. Any attempt to increase dose to CTV increased dose to both rectum and bladder beyond permissible dose. Both anterior perforation in retroverted uterus (Figure 7) and posterior perforation in acutely anteflexed uterus (Figure 8) decreased dose to periphery of CTV due to distancing from uterine tandem. However, CTV dose could be optimized to a higher level in the former, as the tandem was aligned to the cervical canal and was away from rectum.

Table 4. Analysis of possible predisposing factors associated to imperfect insertion out of 292 brachytherapy plans. Fisher's exact test was used to analyze significance of association

\begin{tabular}{|c|c|c|c|}
\hline Factors & Number of good insertions & Number of imperfect insertions & $p$ value \\
\hline \multicolumn{4}{|l|}{ Patient factors } \\
\hline Age $\geq 60$ years & 89 & 4 & 0.365 \\
\hline Parity $\geq 2$ & 185 & 8 & 0.045 \\
\hline History of caesarian section & 42 & 3 & 0.746 \\
\hline \multicolumn{4}{|l|}{ Anatomical and disease factors } \\
\hline Stage IIIB disease & 162 & 11 & 0.868 \\
\hline Large residual tumor mass & 51 & 12 & $<0.001$ \\
\hline Acute anteversion & 15 & 4 & 0.022 \\
\hline Retroversion & 48 & 4 & 0.538 \\
\hline Small uterus & 54 & 5 & 0.376 \\
\hline Stenotic os & 38 & 2 & 1.000 \\
\hline Extremely narrow vagina & 0 & 3 & $<0.001$ \\
\hline \multicolumn{4}{|l|}{ Treatment factors } \\
\hline Preplanning not done & 231 & 10 & 0.005 \\
\hline Interdigitating BT with EBRT & 12 & 3 & 0.056 \\
\hline
\end{tabular}

$B T$ - brachytherapy, EBRT - external beam radiation therapy 

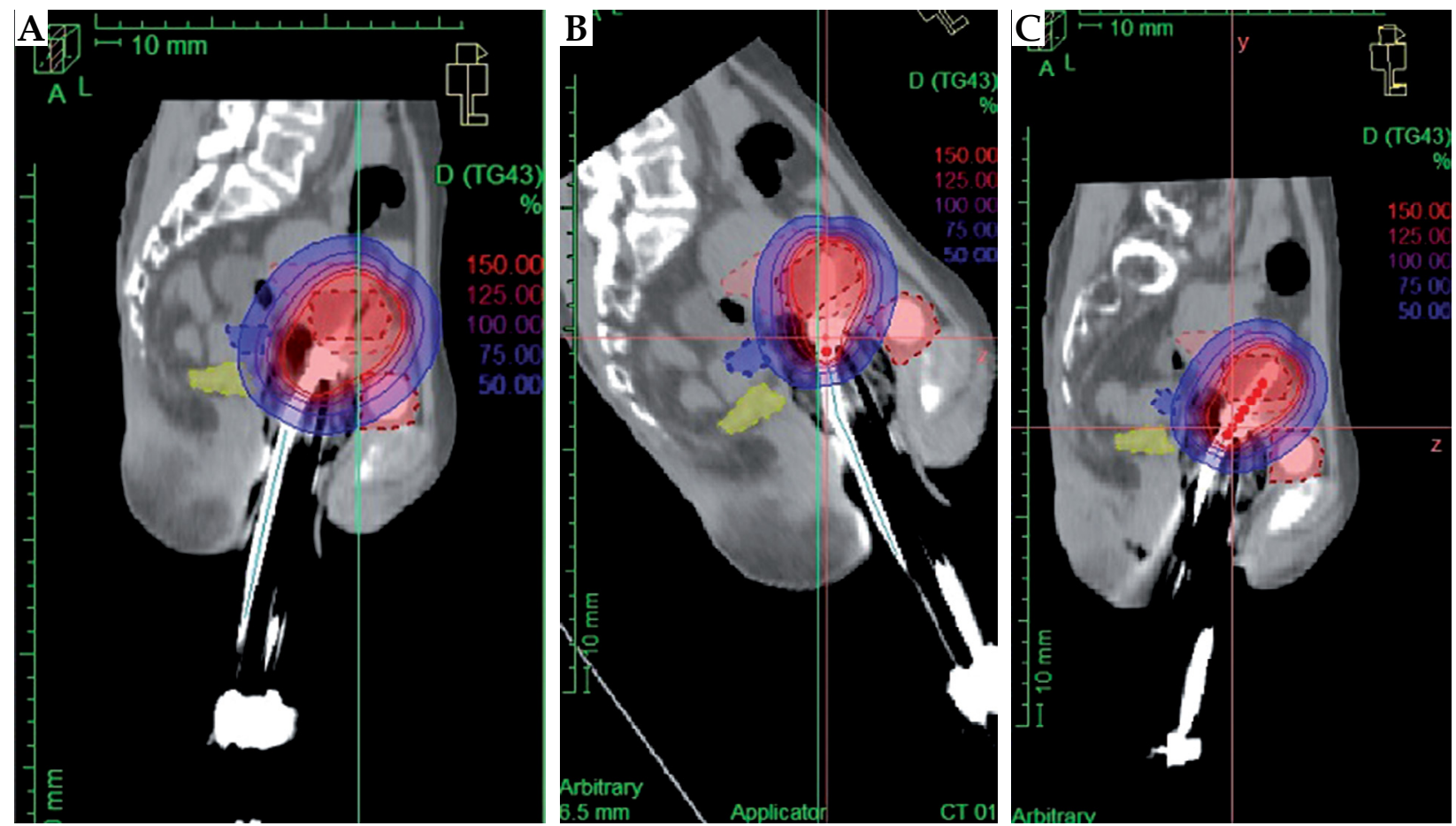

Fig. 2. Effects of normalization in same insertion and planning image set, when uterine tandem is deviated from uterine axis. Dose distribution generated after A) unnormalized optimization, B) normalization to applicator point, and C) normalization to uterine point. Normalization shifts dose from contoured clinical target volume to point of normalization

Table 5. Effect of normalization on dose volume parameters when there was imperfect alignment of tandem to uterine axis. A uniform prescription dose of 7 Gy to $100 \%$ isodose line was done in all cases. Non-parametric (Friedman) test was used to analyze significance

\begin{tabular}{lcccccccc}
\hline & \multicolumn{2}{c}{ Un-normalized plan } & \multicolumn{2}{c}{$\begin{array}{c}\text { Normalized to applicator } \\
\text { point A }\end{array}$} & \multicolumn{2}{c}{$\begin{array}{c}\text { Normalized to patient } \\
\text { point A }\end{array}$} & $p$ value \\
\cline { 2 - 9 } & Median dose (Gy) & SD & Median dose (Gy) & SD & Median dose (Gy) & SD & \\
\hline $\mathrm{D}_{90}$ GTV & 6.21 & 4.23 & 5.55 & 3.51 & 6.94 & 4.72 & 0.121 \\
\hline $\mathrm{D}_{90}$ CTV & 3.72 & 1.87 & 3.33 & 1.34 & 4.19 & 2.30 & 0.121 \\
\hline $\mathrm{D}_{2 \text { cc }}$ rectum & 4.39 & 1.33 & 4.67 & 3.15 & 5.26 & 2.91 & 0.121 \\
\hline $\mathrm{D}_{2 \text { cc }}$ urinary bladder & 5.29 & 1.04 & 5.14 & 1.45 & 6.17 & 2.11 & 0.121 \\
\hline $\mathrm{D}_{2 \text { cc }}$ sigmoid colon & 3.19 & 1.68 & 4.04 & 3.14 & 3.43 & 1.54 & 0.236
\end{tabular}

GTV - gross target volume, CTV - clinical target volume, VOI - volume of interest, $D_{90}$ - dose to $90 \%$ of volume, $D_{2 c c}$ - dose to $2 c c$ volume, SD - standard deviation

CTV dose was adequate after central fundal perforations, as tandem was aligned to uterine axis. However, longer activation of tandem generated high-dose to all VOI. Hence, careful optimization was needed.

\section{Dose to contoured organs at risk}

Judicious activation of dwell positions was necessary to avoid unwanted high-dose application to organs at risk. After satisfactory insertion, dose restrictions to rectum and urinary bladder are possible, when there are satisfactory vaginal packing and adequate emptying of the organs. All cases of posterior perforation resulted in high-dose to both rectum and urinary bladder. Possible explanation of urinary bladder getting high-dose in poste- rior perforation could be pushing of bladder downwards close to ovoids by acute anteflexion of uterus (Figure 3A), which was associated with most cases. On the other hand, in anterior perforation, bladder received high-dose only in $40 \%$ (two out of five) and rectum in $20 \%$ (one out of five cases). These received higher dose only when full or close to uterine body. Careful optimization was needed in that situation. In short insertion, $\mathrm{D}_{2 \mathrm{cc}}$ of all contoured organs at risk were low.

Due to its high up location, sigmoid colon received dose only from upper part of uterine tandem. Thus, it received higher dose only with longer activation of tandem in central fundal perforation. Lower dose was received in both anterior and posterior deviation of tandem. 
Table 6. Comparison of dose volume parameters (presenting median dose to volumes of interest) between improper insertions in different patients. Data was obtained from a repeated three-dimensional treatment planning in these patients with uniform prescription of $7 \mathrm{~Gy}$

A. Dose volume effects of deviation of tandem from uterine axis

\begin{tabular}{|c|c|c|c|}
\hline VOI (dose) & Anterior deviation & Posterior deviation & Centrally aligned tandem \\
\hline GTV $\left(D_{90}\right)$ & 4.07 Gy (58\%) & 3.51 Gy (50\%) & 5.87 Gy $(84 \%)$ \\
\hline CTV $\left(D_{90}\right)$ & 3.56 Gy (51\%) & 1.39 Gy (20\%) & 5.09 Gy (73\%) \\
\hline Rectum $\left(D_{2 c c}\right)$ & 3.92 Gy (56\%) & 5.73 Gy (82\%) & 5.73 Gy $(82 \%)$ \\
\hline Urinary bladder $\left(D_{2 c c}\right)$ & 6.66 Gy $(95 \%)$ & 5.56 Gy $(79 \%)$ & 6.39 Gy (91\%) \\
\hline Sigmoid colon $\left(D_{2 c c}\right)$ & 2.04 Gy (29\%) & 0.81 Gy (12\%) & 1.92 Gy $(27 \%)$ \\
\hline \multicolumn{4}{|c|}{ B. Dose volume effects of residual mass } \\
\hline VOI (dose) & Posterior perforation & Central tandem & Anterior perforation \\
\hline GTV $\left(D_{90}\right)$ & 3.67 Gy $(52 \%)$ & 7.13 Gy $(102 \%)$ & 4.94 Gy $(71 \%)$ \\
\hline $\operatorname{CTV}\left(D_{90}\right)$ & 2.03 Gy $(29 \%)$ & 6.32 Gy $(90 \%)$ & 4.27 Gy (61\%) \\
\hline Rectum $\left(D_{2 c c}\right)$ & 4.65 Gy $(66 \%)$ & 2.90 Gy (42\%) & 3.42 Gy (49\%) \\
\hline Urinary bladder $\left(\mathrm{D}_{2 \mathrm{Cc}}\right)$ & 5.13 Gy $(73 \%)$ & 6.33 Gy $(90 \%)$ & 5.06 Gy $(72 \%)$ \\
\hline Sigmoid colon $\left(D_{2 c c}\right)$ & 5.40 Gy $(77 \%)$ & 4.93 Gy (70\%) & 4.18 Gy $(60 \%)$ \\
\hline \multicolumn{4}{|c|}{ C. Dose volume effects of length of inserted tandem } \\
\hline VOI (dose) & $\begin{array}{l}\text { Central perforation through } \\
\text { fundus }\end{array}$ & Insertion of adequate length & Short insertion \\
\hline GTV $\left(D_{90}\right)$ & 14.36 Gy $(205 \%)$ & 9.01 Gy (129\%) & 3.75 Gy $(54 \%)$ \\
\hline CTV $\left(D_{90}\right)$ & 5.26 Gy $(75 \%)$ & 7.35 Gy (105\%) & 1.16 Gy (17\%) \\
\hline Rectum ( $\left.D_{2 c c}\right)$ & 5.90 Gy (84\%) & 3.57 Gy (51\%) & 4.82 Gy $(69 \%)$ \\
\hline Urinary bladder $\left(\mathrm{D}_{2 \mathrm{cc}}\right)$ & 4.18 Gy $(60 \%)$ & 3.45 Gy (49\%) & 0.89 Gy (13\%) \\
\hline Sigmoid colon $\left(D_{2 c c}\right)$ & 2.23 Gy (32\%) & 5.01 Gy $(72 \%)$ & 2.26 Gy (32\%) \\
\hline \multicolumn{4}{|c|}{ D. Dose volume effects of alternative applicator insertion in a patient having very narrow vagina } \\
\hline VOI (dose) & Sole tandem insertion & Tandem-single ovoid insertion & $\begin{array}{l}\text { Needle implant through fornix } \\
\text { along with uterine tandem }\end{array}$ \\
\hline GTV $\left(D_{90}\right)$ & 8.56 Gy (122\%) & 9.62 Gy (137\%) & 7.08 Gy (101\%) \\
\hline CTV $\left(D_{90}\right)$ & 6.67 Gy (95\%) & 6.64 Gy (95\%) & 6.16 Gy (88\%) \\
\hline Rectum $\left(D_{2 c c}\right)$ & 3.84 Gy (55\%) & 4.58 Gy $(66 \%)$ & 5.06 Gy (72\%) \\
\hline Urinary bladder $\left(\mathrm{D}_{2 \mathrm{cc}}\right)$ & 6.60 Gy (94\%) & 5.90 Gy (84\%) & 4.60 Gy $(66 \%)$ \\
\hline Sigmoid colon $\left(D_{2 c c}\right)$ & 3.92 Gy (56\%) & 4.01 Gy (57\%) & 3.71 Gy (53\%) \\
\hline
\end{tabular}

GTV - gross target volume, CTV - clinical target volume, VOI-volume of interest, $D_{90}$-dose to $90 \%$ of volume, $D_{2 c c}$ - dose to 2 cc volume Dose expressed as percentage of 7 Gy prescribed dose is shown within parenthesis.

Although perfect intracavitary brachytherapy insertion was not possible in the patient with very narrow vagina, all plans after three alternative applicator insertions were dosimetrically acceptable. Optimized dose distribution was slightly improved after tandem along with single ovoid insertion than solitary tandem insertion. Implanting limited number of interstitial needles through fornices along with intra-uterine tandem, generated a little higher dose to rectum (Table 6D, Figure 9).
Review of original treatment plans with actually delivered brachytherapy dose even after imperfect insertion

Eight out of nine patients of perforation having obstructed cervical mass were subjected to subsequent attempt for successful insertion, except the patient who developed metastatic disease after perforation. Subsequent insertions were perfect and dose volume param- 

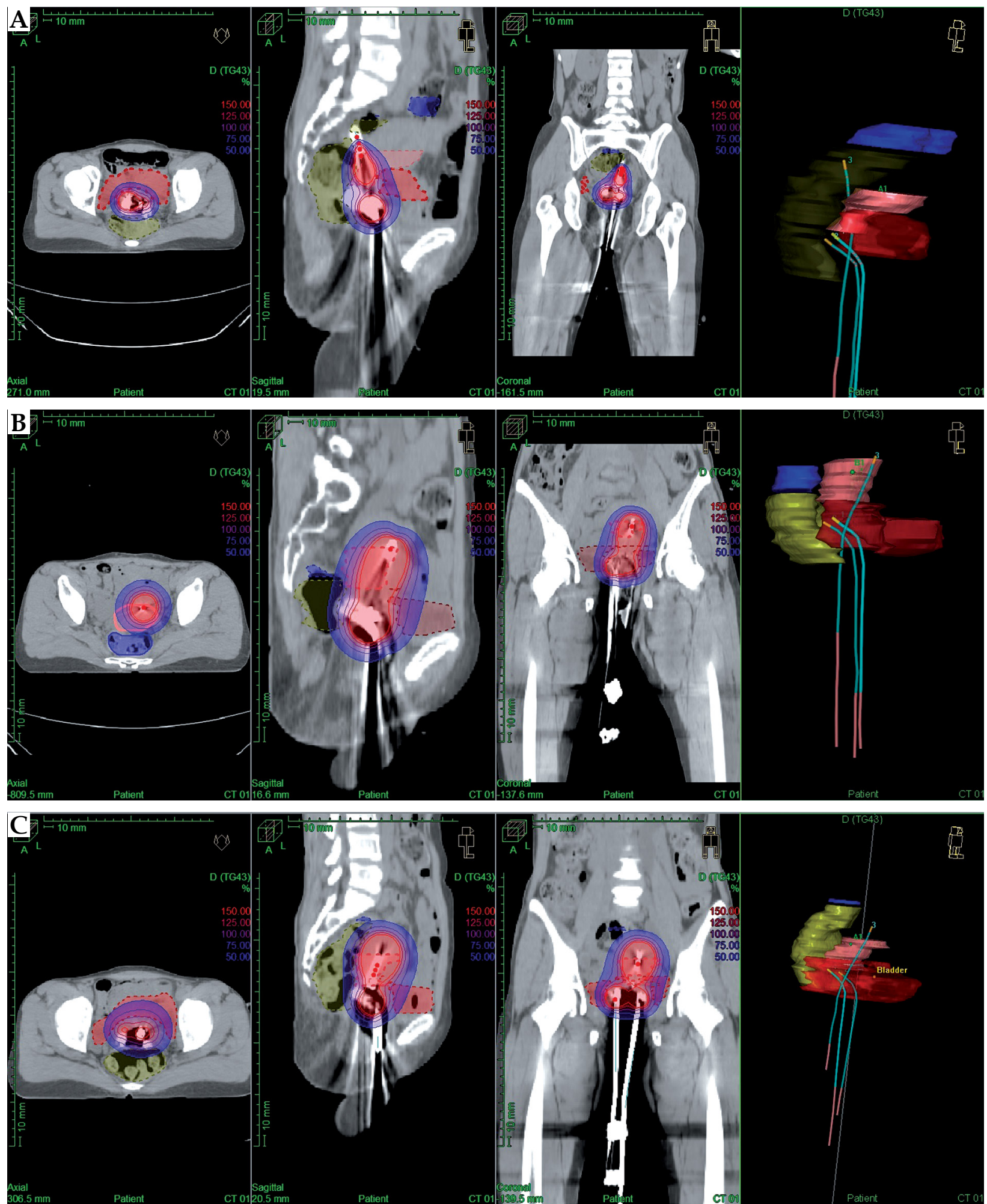

Fig. 3. Dose distribution after inappropriate alignment of uterine tandem with its axis. A) posterior deviation or B) anterior deviation of tandem causes under-dose to periphery of contoured target volume; C) proper alignment of tandem minimizes chances of peripheral miss

eters were acceptable in six out of these eight cases (Figures 4 and 5). All of them had received full prescribed dose to at least $60 \%$ volume of the tumor mass $\left(D_{60}\right)$ after perforation $\left(D_{60} \geq 100 \%\right)$. This was seen where tandem was aligned more or less centrally close to the mass. Other two patients who had received $D_{60}<100 \%$ in the imperfect insertion also had CTV dose inadequacy in their subsequent insertion. Statistical analysis by Fisher's 

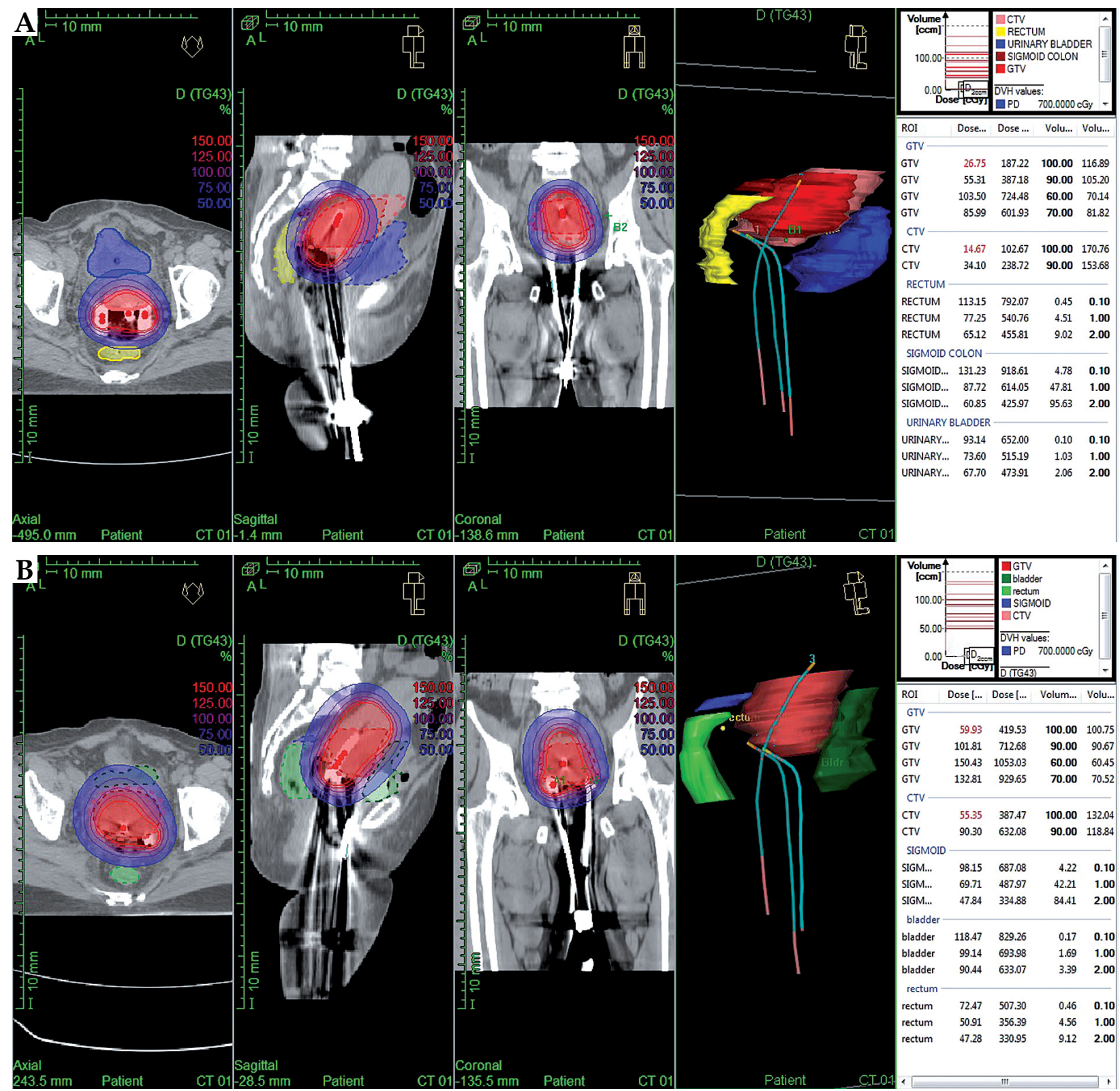

Fig. 4. Delivery of full planned prescription dose to at least $60 \%$ of obstructing cervical mass in (A) defective insertion with posterior perforation causes (B) good subsequent insertion with acceptable dose volume parameters

exact test revealed that this association (between delivery of full prescribed dose to $60 \%$ of obstructing mass during imperfect insertion and successful subsequent insertion along-with acceptable dose volume parameters) was significant $(p<0.001)$.

Dose inadequacy was observed mostly in cases of acute anteflexion of uterus, with either short insertion or posterior perforation. Correction of anteflexion before subsequent insertions generated good dose volume parameters (Table 7A, Figure 8). In cases with uncorrectable retroversion of uterus, subsequent insertions were successful and good dose volume optimization was achieved after placement of tandem aligned to uterine axis in a retroverted direction, provided that vaginal packing and bowel preparation were adequate (Table 7B, Figure 7).

\section{Discussion}

Uterine perforation is a potential complication of all intrauterine procedures and may be associated with injury of bowel, bladder, or surrounding blood vessels hemorrhage or sepsis [13]. In case of malignancy, the tissues may be friable and prone to perforation owing to the cancer itself and the usual use of prior external beam radiotherapy [14]. The incidence of uterine perforation is based on self-report by surgeons, and it is likely that any reported incidence is underestimated [13]. Literature review divulges incidence of uterine perforation varying from $2.8 \%$ to $13.7 \%$ $[15,16]$. It is often undetected by orthogonal imaging and even clinical examination [17]. CT detected perforation is seen in $8.2 \%$ of insertions, where the radiation oncologist is clinically confident of correct tandem placement [16]. 

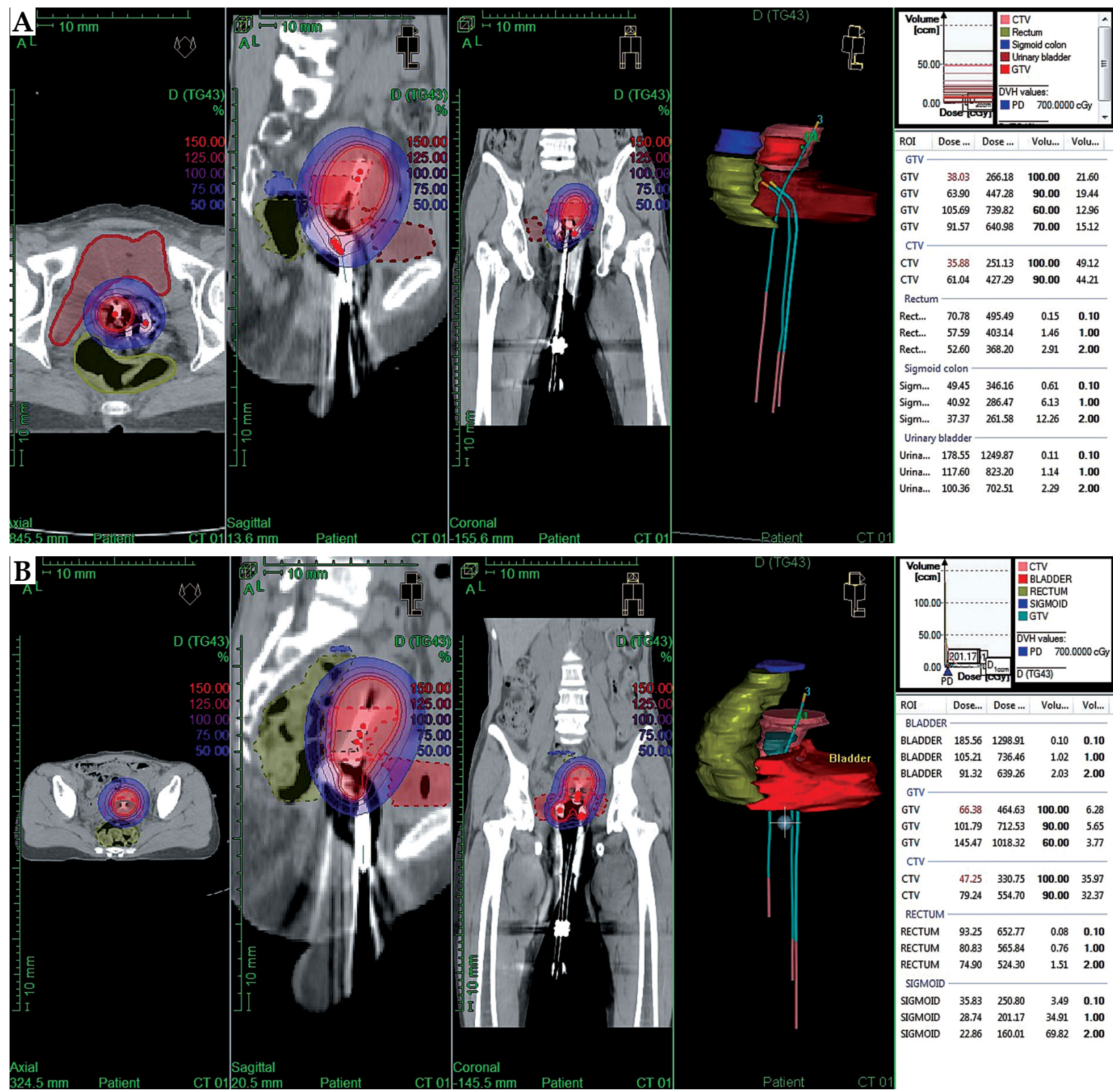

Fig. 5. Delivery of full planned prescription dose to at least $60 \%$ of obstructing cervical mass in (A) defective insertion with anterior perforation causes (B) good subsequent insertion with acceptable dose volume parameters

Onal et al. in their study [18] emphasized that older age, larger tumors, retroverted uterus, and a stenotic cervical os are all predisposing factors for uterine perforation. In their study, $57 \%$ of the patients with a retroverted uterus had uterine perforation. Other studies established age more than 60 years $[16,19,20]$, history of prior conization [19,21], physician inexperience [20], scarring or distortion of the cervical os $[16,19,22]$, and increasing tumor size [16] as risk factors for uterine perforation.

The most frequent perforation site is the posterior uterine wall $(4 \%)$, followed by the fundus $(2.5 \%)$ and anterior wall (2\%) [18]. Perforation with a blunt sound or dilator through fundus is usually asymptomatic, and perforation through cervix even with blunt probe is more prone to complications. Damage to bladder, rectum, or lateral vessels may occur [23]. The use of traditional X-ray simulations may make the planner not aware to the true position of the central tandem, which if loaded in the intra-abdominal location that could expose the small intestine to risk of serious radiation dosages [24].

South Indian institutional experience by Rao et al. reported that ultrasound (US) guidance helped in accurate identification of cervical os and made uterine sounding possible when cervix was flushed with vagina. It also suggested that intraoperative ultrasound helped in identifying the patients suitable for interstitial brachytherapy rather than intracavitary brachytherapy [25]. With intraoperative US guidance, reported incidence of perforation were reduced to $0.9-1.4 \%[26,27]$. Visualizing patient anatomy during insertion altered 

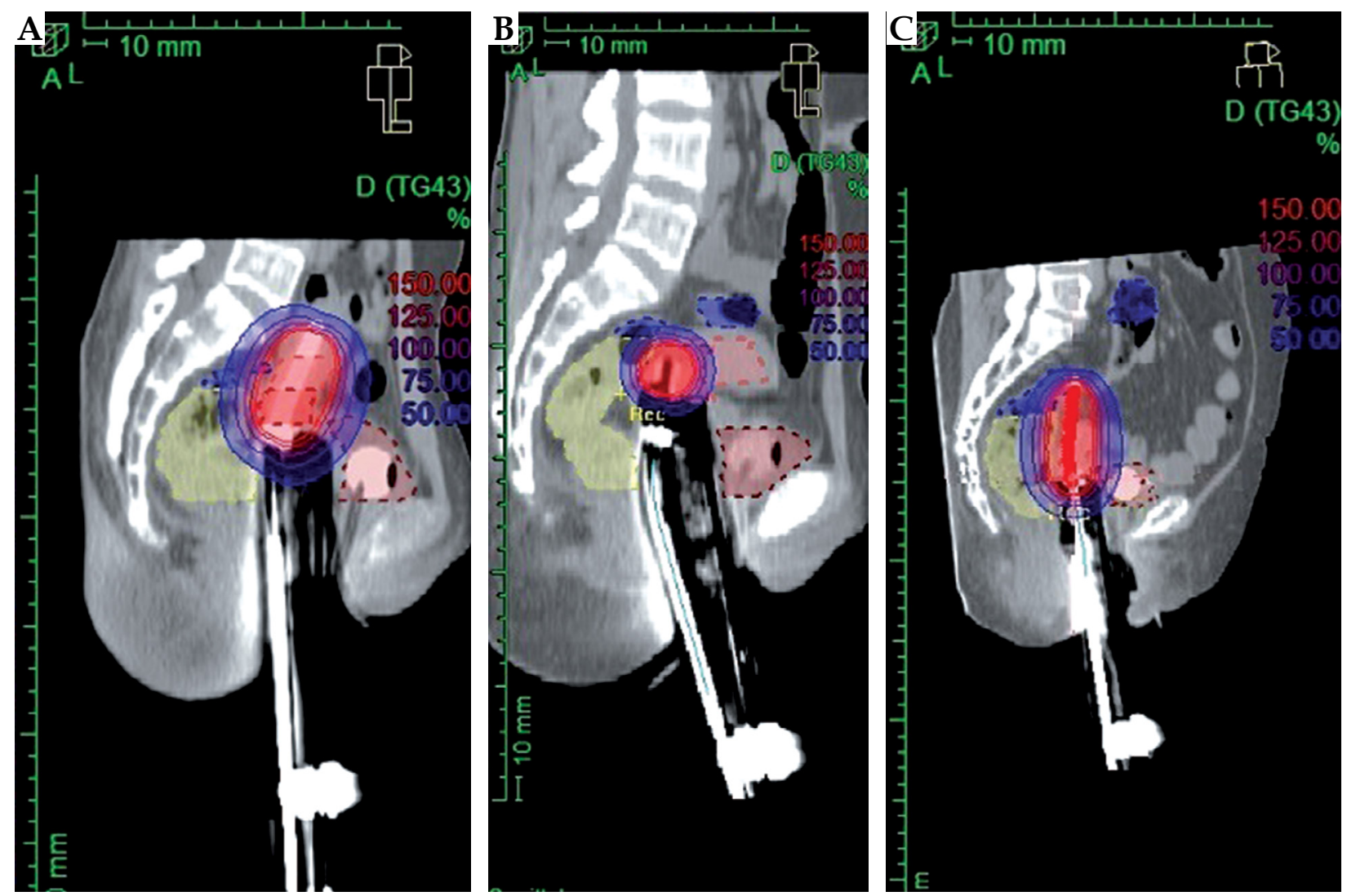

Fig. 6. The importance of insertion of appropriate length of uterine tandem. A) Good insertion; B) short insertion in uncorrected acute anteflexion of uterus causing under-dose to periphery of target volume; C) fundal perforation - there is chance of highdose to organs at risk if activation of tandem is done for a longer length

the selection of tandem length and angle in $49 \%$ of cases, resulting in improved applicator matching to anatomy [28]. Moreover, ultrasound-guided anteversion of the inserted tandem and uterus was achieved in most patients with retroverted uterus [29]. However, even with US guidance, tandem length was short in $0.9 \%$ and tandem was in myometrium in another $0.9 \%$ [26]. Interestingly, some series of high-risk patients have demonstrated perforation rates of up to $30 \%$ despite the use of intraoperative ultrasound $[20,22]$. However, these series specifically employed ultrasonography in high-risk situations. Further, following a 'learning curve' period, no further perforations were noted in one of these series [20]. Even though ultrasound-guidance is known to reduce the risk of uterine perforation, it is not yet used routinely by many clinicians [28]

Study by Onal et al. revealed that preoperative magnetic resonance imaging (MRI) planning reduces incidence of perforation to $4 \%$ from $11 \%$ without pre-planning [18]. Study by Lim et al. discovered that laparoscopy-assisted placement of an ICR tandem allowed optimal implementation of brachytherapy in difficult cases $(2.6 \%)$ without causing significant morbidity [30].

Published data on the effect of mal-placement of brachytherapy applicators on clinical outcome and plan quality are scarce [29]. In a study, Viswanathan et al. showed that inappropriate placement of brachytherapy applicators led to significant risk of local recurrence (2.5 times) and lower disease-free survival rate (2.28 times) [31]. A study by Bahadur et al. emphasized that $\mathrm{D}_{90}$ significantly decreased with average of $-115.7 \% \pm 134.9 \%$ for uterine perforation and $-65.2 \% \pm 82.8 \%$ for sub-serosal insertion $(p=0.025)$. The rectum and bladder dose assessed by $\mathrm{D}_{2 \mathrm{cc}}$ increased up to $70.3 \%$ and $43.8 \%$, respectively [32]. But in this study, neither statistical analysis nor study of clinical effects were done. No studies till date suggested treatment decision after imperfect insertions in patients having difficult anatomy (such as residual obstructing mass, acute anteflexion, fixed retroversion, narrow vagina etc.), which will guide to a good subsequent insertion with acceptable dose volume parameters.

In our study, faulty insertions were seen in $6.2 \%$, including uterine perforation in $4.5 \%$ cases. Lack of pre-planning by imaging to determine uterine size and position, and to determine location of obstructing cervical mass, presence of obstructing cervical mass itself and extremely narrow vagina were significant predisposing factors for atypical insertions $(p<0.05)$. Residual cervical mass was associated with almost all cases of uterine perforation. Perforation through uterine body musculature was more common than through friable cervical mass. Anterior perforation was mostly seen in patients having fixed retroverted uterus. Either acute anteflexion of uterus or cervical os hidden behind anterior lip of cervix of an anteverted uterus caused posterior perforation. All cases of central fundal perforation had small uterus. Most of the documented cas- 

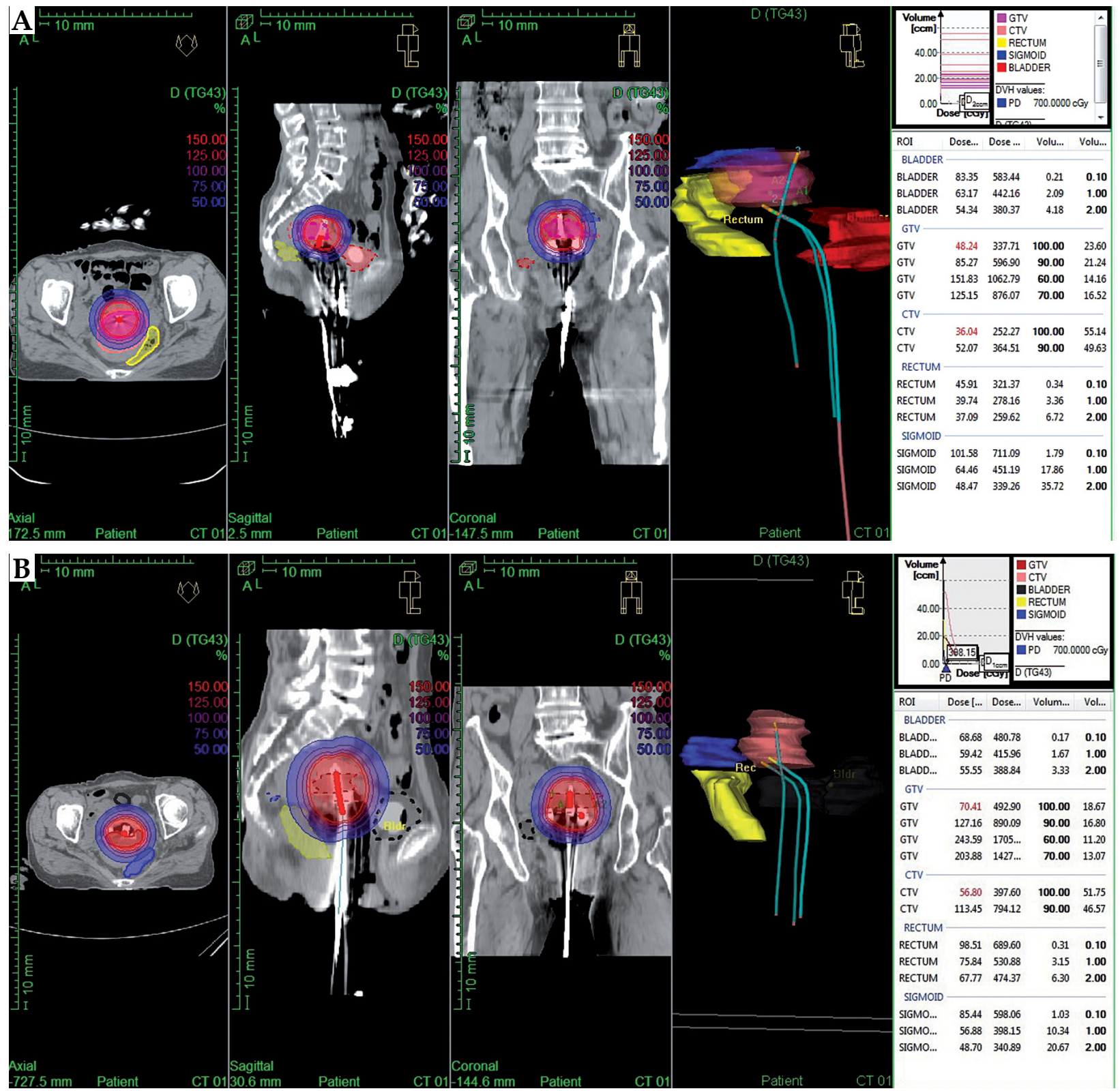

Fig. 7. Dose volume parameters after (A) anterior perforation in uncorrectable retroverted uterus, B) insertion of uterine tandem in retroverted direction in subsequent insertion. Insertion of uterine tandem in retroverted direction creates acceptable and better dose volume parameters

es of perforation were manageable after close observation. No damage of bowel or bladder was detected.

Even after best attempts for optimization during repeat dosimetry, anterior or posterior deviation of tandem and short tandem insertions resulted in lower dose to CTV. All cases of posterior perforation resulted in highdose applications to both rectum and urinary bladder. On the other hand, in anterior perforation, bladder received high dose only in $40 \%$ and rectum in $20 \%$ cases. These received higher dose only when full or close to uterine body. After insertion of shorter length of uterine tandem, $\mathrm{D}_{2 \mathrm{cc}}$ of all contoured organs at risk were low. Sigmoid colon received higher dose only in longer activation of tandem after central fundal perforation. In the patient with extremely narrow vagina, optimization after tandem along with single ovoid insertion created better dose distribution than solitary tandem insertion. Unnormalized optimization showed good dose conformity in almost all instances of imperfect insertions.

After faulty insertion due to obstructing cervical mass, good subsequent insertions along with acceptable dose volume parameters were possible only if planned treatment dose could be delivered to at least $60 \%$ of the obstructing mass, with careful optimization after an imperfect insertion. This was seen where tandem was aligned approximately centrally close to the mass. Insertion of tandem aligned to central axis generated good dose distribution after correction of acute anteflexion of uterus or after retroverted placement of the tandem in uncorrectable retroverted uterus. 

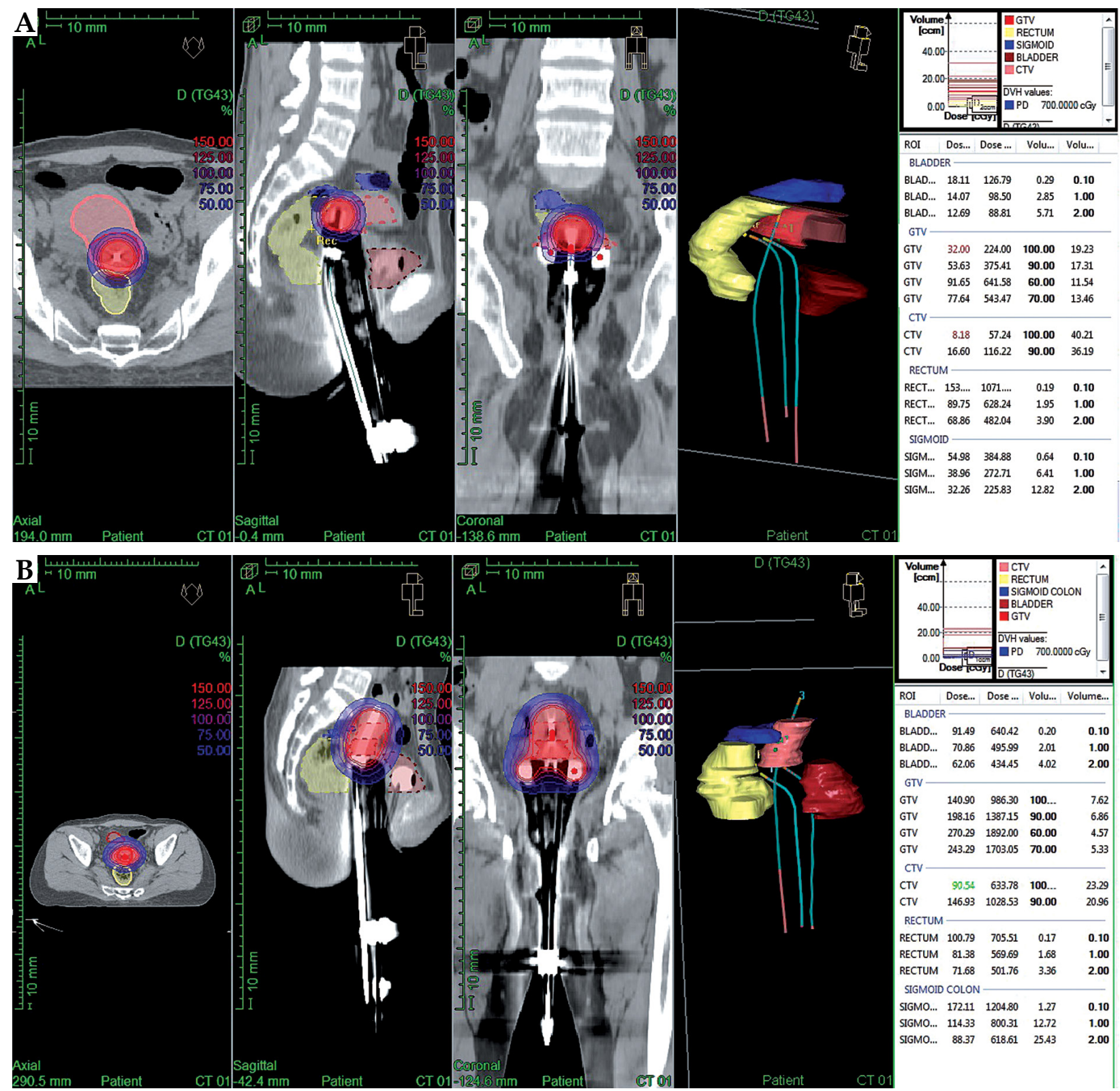

Fig. 8. Dose volume parameters generated without and with correction of acute anteflexion of uterus in a patient. A) Short insertion in uncorrected acute anteflexion causes under-dose to target volume. B) Good dose volume parameters are generated after correction of anteflexion

\section{Conclusions}

Pre-planning by imaging before insertion is needed to assess length, direction, and position of uterine cavity as well to determine location of any residual cervical mass. This minimizes chance of brachytherapy insertion becoming imperfect. Insertion of adequate length of tandem aligned to uterine axis is warranted for appropriate tumor coverage by prescribed dose. Whenever detected, acute anteflexion and mobile retroversion should be corrected to ensure proper positioning of applicators. However, tandem inserted in retroverted direction in uncorrectable retroverted uterus generates acceptable dose volume parameters after proper optimization.
Even after careful insertion, if insertion is imperfect or even if there is perforation, radiation dose delivery may be attempted unless applicator is placed in a completely wrong position. Plan should be graphically optimized to limit dose to rectum, bladder, and sigmoid colon. Normalization at point A should be used with caution if insertion is imperfect, as it may shift optimized dose in an undesired way in cases of improper insertions.

In cases with residual tumor mass obstructing cervical canal, good subsequent insertion with acceptable dose volume parameters is possible if full planned dose can be delivered to $60 \%$ volume of the obstructing mass. Further studies with larger number of patients, preferably with MRI-based target volume delineation, along with assess- 

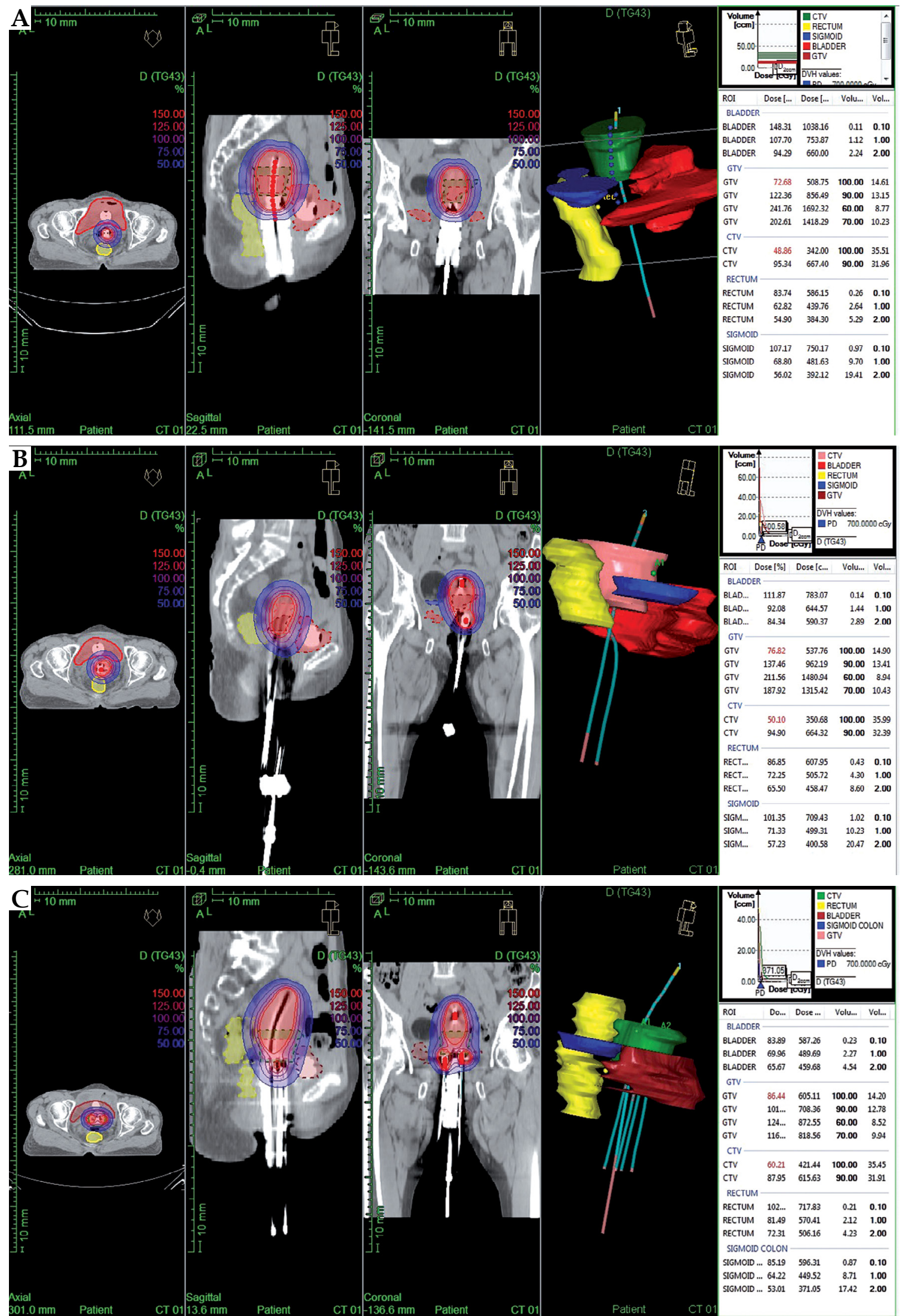

Fig. 9. Dose volume parameters generated using three different insertion techniques applied in a patient with very narrow vagina. A) uterine tandem with four interstitial needle implant through vaginal fornices; B) uterine tandem with solitary ovoid; C) single tandem application. All three techniques generated acceptable dose volume parameters 
Table 7. Comparison of dose volume parameters after three different possible types of insertion in patients having acutely anteverted and fixed retroverted uterus. A repeated three-dimensional treatment planning with uniform prescription of 7 Gy was done for comparability. Type of insertion where planning delivered dose to target volume lower than the planned treatment dose (with an intent to restrict high dose to organs at risk) was considered not preferable

A. Dose volume effects of acute anteflexion of uterus

\begin{tabular}{|c|c|c|c|c|}
\hline & $\begin{array}{c}\text { Median value of dose } \\
\text { to VOI }\end{array}$ & $\begin{array}{c}\text { Posterior perforation } \\
\text { in acutely anteverted } \\
\text { uterus }\end{array}$ & $\begin{array}{l}\text { Short insertion in acutely } \\
\text { anteflexed uterus }\end{array}$ & $\begin{array}{c}\text { Normal insertion after } \\
\text { digital correction } \\
\text { of anteflexion }\end{array}$ \\
\hline GTV & $\mathrm{D}_{90}$ & 2.70 Gy $(39 \%)$ & 3.75 Gy $(54 \%)$ & 13.87 Gy $(198 \%)$ \\
\hline CTV & $\mathrm{D}_{90}$ & 1.95 Gy (28\%) & 1.16 Gy $(17 \%)$ & 10.29 Gy $(147 \%)$ \\
\hline Rectum & $\mathrm{D}_{2 \mathrm{cc}}$ & 6 Gy $(86 \%)$ & 4.82 Gy $(69 \%)$ & 5.02 Gy $(72 \%)$ \\
\hline Urinary bladder & $\mathrm{D}_{2 c c}$ & 6.72 Gy $(96 \%)$ & 0.89 Gy $(13 \%)$ & 4.34 Gy $(62 \%)$ \\
\hline Sigmoid colon & $D_{2 c c}$ & 2 Gy $(29 \%)$ & 2.26 Gy $(32 \%)$ & 6.19 Gy $(88 \%)$ \\
\hline \multicolumn{5}{|c|}{ B. Dose volume effects of uterine retroversion } \\
\hline & $\begin{array}{c}\text { Median value of dose } \\
\text { to VOI }\end{array}$ & $\begin{array}{c}\text { Anterior perforation } \\
\text { in fixed retroverted } \\
\text { uterus }\end{array}$ & $\begin{array}{l}\text { Retroverted placement } \\
\text { of tandem within uterus }\end{array}$ & $\begin{array}{c}\text { Normal insertion after } \\
\text { digital correction } \\
\text { of mobile retroversion }\end{array}$ \\
\hline GTV & $\mathrm{D}_{90}$ & 5.39 Gy $(77 \%)$ & 8.46 Gy $(121 \%)$ & 7.06 Gy $(101 \%)$ \\
\hline CTV & $D_{90}$ & 3.55 Gy (51\%) & 7.73 Gy $(110 \%)$ & 4.97 Gy (71\%) \\
\hline Rectum & $D_{2 c c}$ & 3.30 Gy (47\%) & 4.61 Gy (66\%) & 2.75 Gy (\%) \\
\hline Urinary bladder & $\mathrm{D}_{2 \mathrm{cc}}$ & 5.11 Gy (73\%) & 3.78 Gy (54\%) & 3.12 Gy (45\%) \\
\hline Sigmoid colon & $D_{2 c c}$ & 4.23 Gy (60\%) & 3.33 Gy (48\%) & 3.51 Gy (50\%) \\
\hline
\end{tabular}

GTV - gross target volume, CTV - clinical target volume, VOI - volume of interest, $D_{90}$-dose to $90 \%$ of volume, $D_{2 c c}$-dose to $2 c c$ volume

Dose expressed as percentage of 7 Gy prescribed dose is shown within parenthesis.

ment of clinical response and late toxicities need to be conducted.

\section{Disclosure}

The authors report no conflict of interest.

\section{References}

1. Mongula J, Slangen B, Lambregts D et al. Predictive criteria for MRI-based evaluation of response both during and after radiotherapy for cervical cancer. J Contemp Brachytherapy 2016; 8: 183-190

2. Villalba SR, Sancho JR, Palacín AO et al. Development and clinical implementation of a new template for MRI-based intracavitary/interstitial gynecologic brachytherapy for locally advanced cervical cancer: from CT-based MUPIT to the MRI compatible Template Benidorm. Ten years of experience. J Contemp Brachytherapy 2016; 8: 404-414.

3. Siavashpour Z, Aghamiri MR, Jaberi R et al. Optimum organ volume ranges for organs at risk dose in cervical cancer intracavitary brachytherapy. J Contemp Brachytherapy 2016; 8: 135-142.

4. Basu B, Basu S, Chakraborti B et al. A comparison of dose distribution from Manchester-style and Fletcher-style intracavitary brachytherapy applicator systems in cervical cancer. J Contemp Brachytherapy 2012; 4: 213-218.

5. Chakrabarti B, Basu-Roy S, Kar S et al. Comparison of dose volume parameters evaluated using three forward planning - optimization techniques in cervical cancer brachytherapy involving two applicators. J Contemp Brachytherapy 2017; 9: 431-445.

6. Wang $\mathrm{X}, \mathrm{Li} \mathrm{J}$, Wang $\mathrm{P}$ et al. Image-guided radiation therapy boost in combination with high-dose-rate intracavitary brachytherapy for the treatment of cervical cancer. J Contemp Brachytherapy 2016; 8: 122-127.

7. Otter S, Franklin A, Ajaz M et al. Improving the efficiency of image-guided brachytherapy in cervical cancer. J Contemp Brachytherapy 2016; 8: 557-565.

8. Corn BW, Hanlon AL, Pazak TF et al. Technically accurate intracavitary insertions improve pelvic control and survival among patients with locally advanced carcinoma of uterine cervix. Gynecol Oncol 1994; 53: 294-300.

9. American Brachytherapy Society cervical cancer brachytherapy task group. Viswanathan AN, Thomadsen B. Available at: https://www.americanbrachytherapy.org/guidelines/ cervical_cancer_taskgroup.pdf (Accessed: 20 October 2017).

10. Suneja G, Brown D, Chang A et al. American Brachytherapy Society: Brachytherapy treatment recommendations for locally advanced cervix cancer for low-income and middle-income countries. Brachytherapy 2017; 16: 85-94.

11. Viswanathan AN, Beriwal S, Viswanathan JD. The American Brachytherapy Society Treatment Recommendations for Locally Advanced Carcinoma of the Cervix Part II: High DoseRate Brachytherapy. Brachytherapy 2012; 11: 47-52.

12. Pötter R, Haie-Mederb C, Limbergenc EV et al. Recommendations from gynaecological (GYN) GEC ESTRO working group (II): Concepts and terms in 3D image-based treatment planning in cervix cancer brachytherapy-3D dose volume pa- 
rameters and aspects of 3D image-based anatomy, radiation physics, radiobiology. Radiother Oncol 2006; 78: 67-77.

13. Uterine perforation during gynecologic procedures. Barbara S Levy. Available at https://www.uptodate.com/contents/ uterine-perforation-during-gynecologic-procedures (Accessed: 20 October 2017).

14. Prabhakar GS, Revannasiddaiah S, Susheela SP et al. Uterine perforation during intracavitary brachytherapy for carcinoma of the cervix. BMJ Case Rep 2012. doi:10.1136/bcr-2012007830.

15. Irvin W, Rice $L$, Taylor $P$ et al. Uterine perforation at the time of brachytherapy for carcinoma of the cervix. Gynecol Oncol 2003; 90: 113-122.

16. Barnes EA, Thomas G, Ackerman I et al. Prospective comparison of clinical and computed tomography assessment in detecting uterine perforation with intracavitary brachytherapy for carcinoma of the cervix. Int J Gynecol Cancer 2007; 17: 821-826.

17. Small W Jr, Strauss JB, Hwang CS et al. Should uterine tandem applicators ever be placed without ultrasound guidance? No: a brief report and review of the literature. Int J Gynecol Cancer 2011; 21: 941-944.

18. Onal C, Guler OC, Dolek Y et al. Uterine perforation during 3-dimensional image-guided brachytherapy in patients with cervical cancer: Baskent University experience. Int J Gynecol Cancer 2014; 24: 346-351.

19. Jhingran A, Eifel PJ. Perioperative and postoperative complications of intracavitary radiation for FIGO stage I-III carcinoma of the cervix. Int J Radiat Oncol Biol Phys 2000; 46: 1177-1183.

20. Corn BW, Shaktman BD, Lanciano RM et al. Intra- and perioperative complications associated with tandem and colpostat application for cervix cancer. Gynecol Oncol 1997; 64: 224-229.

21. Kim RY, Levy DS, Brascho DJ et al. Uterine perforation during intracavitary application. Radiology 1983; 147: 249-251.

22. Rotmensch J, Waggoner SE, Quiet C. Ultrasound guidance for placement of difficult intracavitary implants. Gynecol Oncol 1994; 54: 159-162.

23. Perforation with uterine sound and suction cannula during D\&C. Eugene C. Toy. Available at: https://exxcellence.org/ perals-of-exxcellence/list-of-pearls/perforation-with-uterine-sound (Accessed 20 October 2017).

24. Makin WP, Hunter RD. CT scanning in intracavitary therapy: unexpected findings in "straightforward" insertions. Radiother Oncol 1988; 13: 253-255.

25. Rao PB, Ghosh S. Routine use of ultrasound guided tandem placement in intracavitary brachytherapy for the treatment of cervical cancer - a South Indian institutional experience. J Contemp Brachytherapy 2015; 7: 352-356.

26. Akbas T, Ugurluer G, Acil M et al. Intraoperative sonographic guidance for intracavitary brachytherapy of cervical cancer. J Clin Ultrasound 2018; 46: 8-13.

27. Schaner PE, Caudell JJ, De Los Santos JF et al. Intraoperative ultrasound guidance during intracavitary brachytherapy applicator placement in cervical cancer: The University of Alabama at Birmingham experience. Int J Gynecol Cancer 2013; 23: 559-566.

28. Davidson MT, Yuen J, D'Souza DP et al. Optimization of highdose-rate cervix brachytherapy applicator placement: the benefits of intraoperative ultrasound guidance. Brachytherapy 2008; 7: 248-253.

29. Mayr NA, Montebello JF, Sorosky JI et al. Brachytherapy management of the retroverted uterus using ultrasound-guided implant applicator placement. Brachytherapy 2005; 4: 24-29.
30. Lim MC, Jung DC, Kim JY et al. Laparoscopy-assisted intracavitary radiotherapy tandem placement for patients with cervical cancer. Int J Gynecol Cancer 2009; 19: 1125-1130.

31. Viswanathan AN, Moughan J, Small W et al. The quality of cervical cancer brachytherapy implantation and the impact on local recurrence and disease-free survival in radiation therapy oncology group prospective trials 0116 and 0128 . Int J Gynecol Cancer 2012; 22: 123-131.

32. Bahadur YA, Eltaher MM, Hassouna AH et al. Uterine perforation and its dosimetric implications in cervical cancer high-dose-rate brachytherapy. J Contemp Brachytherapy 2015; 7: $41-47$. 